\author{
ALENA KALECHYTS
}

\title{
Прагматическая функция интертекстем в веб-медиатекстах белорусских и российских интернет-СМИ*
}

\section{The pragmatic function of intertextemes in digital media texts of the Belarusian and Russian mass media}

\begin{abstract}
The article discusses the features of the functioning of phraseological units and other stable combinations in the headings of the media texts of Belarusian and Russian online newspapers. We analyze the pragmatic function of intertexts and present them as pointers to certain types of speech acts. The intent of the addressee is the most important factor in creating a text. It is usually reflected, directly or indirectly, in every communication product. The main purpose of media texts (or a hint of it) is contained in headings, especially when they are intertextemes, various renewable speech units that we classify according to the types of speech acts: representatives, rogatives, directives, commissives, contactives, declarations and expressives. Such headings are best used to perform a pragmatic function because they retain an emotional and evaluation component that stimulates communication with the mass recipient. These stable units (phraseological locutions, winged expressions and aphorisms, paroemias and compound terms) comprise the background knowledge of the participants in communication and are therefore productive language tools used by journalists in their practice. And very often the intertextemes are transformed or updated. Employees of "BelGazeta" and "Rossiyskaya Gazeta" use both the general phraseological fund of Belarusians and Russians and the national language means in web media texts. The headlines of "BelGazeta" have a distinctive feature, as they mix graphic and lexical systems of different languages (Russian, Belarusian, English and, less frequently, Ukrainian). This fact can be explained, firstly, by the tendency to widely spread the features of the conversational speech of Belarusians, trasyanka, in book speech styles. And, secondly, by the address policy of the publication of the named newspaper, which is aimed at the mass Belarusian reader. Following the use of occasionalisms, updated stable expressions, we also call the above feature a specific method of influencing the addressee.
\end{abstract}

Keywords: intertextemes, digital media texts, mass media, idiom, pragmatic function, transformation, grammatical indicators, pragmatics

Alena Kalechyts, Constantine the Philosopher University in Nitra, Nitra - Slovakia, akalechyts@ ukf.sk, ORCID ID: https://orcid.org/0000-0002-5738-7168

* Данная работа выполнена в рамках проекта VEGA № 1/0067/19 „Jazykové reflexie sociálnej egoprezentácie a adresácie" (Словакия). 
Известно, что у истоков развития прагматики как науки стояли такие известные философы, как Платон, Аристотель, Джон Лэнгшо Остин, Джон Роджерс Серль, Людвиг Витгенштейн, Герберт Пол Грайс, Павел Александрович Флоренский, Алексей Федорович Лосев и мн. др. Кроме того, особенный вклад в разработку целенаправленного использования языковых средств в речи внесли выдающиеся филологи: Аврам Ноам Хомский, Эдуард Сепир, Татьяна Григорьевна Винокур, Вильгельм фон Гумбольдт, Юрий Михайлович Лотман, Маршал Маклюэн, Фердинанд де Соссюр, Роман Осипович Якобсон, Валерий Петрович Даниленко, Наталья Ивановна Формановская и т. д. Так, благодаря возникшему интересу к способности языковых знаков влиять на поведение воспринимающих, стало возможным развитие семиотики, усилия языковедов сосредоточились на более глубоком понимании семантики и синтактики. Структура и тактики речевого поведения нашли отражение в теории речевых и коммуникативных актов и концепции коммуникативной рациональности. Формы речевой коммуникации, соотношение мышления и речи, роль языка в общественной деятельности человека, основы рекламы и потребления товаров, отношения между участниками образовательного процесса и т. д. - все это стало предметом изучения и анализа психологов и педагогов: Роберта Бернса, Отто Фридриха Больнова, Мартина Бубера, Людмилы Михайловны Лузиной и др. Работы этих и многих других зарубежных и российских ученых указывают на степень изученности данного вопроса и основные направления дальнейшего развития (Menŝikova 3-6).

По мнению многих исследователей, и в частности Дмитрия Владимировича Некрасова, главным „в процессе создания текста является замысел говорящего" (Nekrasov 119). Цель, которую он преследует, может быть следующей: сообщить информацию, побудить к действию, пообещать, выразить свое психическое состояние, сделать объявление, задать вопрос, установить контакт и т. д. Именно от этого будет зависеть, каким станет текст, какую структуру и композицию он приобретет, в каком стиле будет написан и т. д. Важным фактором при создании текста, безусловно, является его адресат, поскольку адресант, вступая в общение, всегда учитывает ситуацию коммуникации и то, кому именно направлено высказывание. Причем адресат может быть как реальным и гипотетическим, так и обобщенным и прогнозируемым, а также массовым, публичным, конкретизируемым, персональным, единичным, конкретным и косвенным (или вторичным) адресатом (Formanovskaâ 77). Если публицистический текст имеет четкую профессиональную ориентацию, то и адресат будет представляться журналисту достаточно реальным человеком с конкретными интересами, уровнем образования и т. д. В том случае, когда речь идет о массовой коммуникации, осуществляемой через информационные и/или аналитические СМИ, журналист, скорее все- 
го, спрогнозирует реципиента и в своих работах будет использовать общий фонд знаний и речевых средств, знакомый и понятный для большинства его сограждан.

Сеть Интернет считается самым современным медиаресурсом, а продукты СМИ, распространяемые через электронные носители, являются медиатекстами, отличающимися от обычных текстов гипертекстуальностью, интертекстуальностью, поликодовостью, многофункциональностью, незавершенностью и некоторыми другими особенностями (Parzulova 16-17). Для различия источников полученной информации ученые предлагают такие тексты называть гипермедиатекстами, или веб-медиатекстами. Таким образом, в значение этих понятий они включают наличие нетекстовых компонентов: звука, изображения, гиперссылки и др. (Kuz'mina 255). Это смешанные тексты, так как в них сочетаются вербальные и невербальные средства передачи информации. На наш взгляд, наиболее удачным наименованием таких медиатекстов является веб-медиатекст, поскольку часть термина - веб - имеет значение 'интернет-пространство, всемирная паутина'. На этом основании в своей работе мы будем использовать данное специальное понятие, поскольку объектом нашего исследования являются интернет-версии известных в Беларуси и России печатных изданий „БелГазеты” и „Российской газеты” за 2018 год.

И „БелГазета”, и „Российская газета” - еженедельные массмедиа. Однако „Российская газета” - это еще и ежедневник. Они стали выходить в печать, приблизительно, в одно и то же время, в 90-е годы XX в.: „Российская газета” - с 1990 г., а „БелГазета” - с 1995 г. Правда, до 2005 г. она носила название „Белорусская газета”. Обе газеты имеют печатную и электронную версии (https://rg.ru/; https://www.belgazeta.by/). В „Российской газете” читателям предлагаются материалы только на русском языке, в „БелГазете”, кроме русскоязычных статей, встречаются тексты, написанные по-белорусски. „Российскую газету” можно назвать многофункциональным изданием, поскольку в ней не только печатаются новости, аналитические статьи и различные репортажи, но и законы, указы, государственные документы - таким образом, она еще исполняет роль печатного правительственного публикатора (с 1994 г.). Кроме того, названная газета имеет развлекательную функцию: на последней странице ее печатной версии размещаются анекдоты, сканворды, судоку, гороскопы и викторины. „БелГазета” сохраняет статус только информационно-аналитической газеты. В ней можно познакомиться с новостями, прочитать критические материалы известных белорусских журналистов и писателей на злобу дня. Электронная версия данных СМИ предлагает заинтересованным посетителям сайта подписаться на блоги своих сотрудников. На основании того, что обе онлайн-версии газет имеют 
много общего, предметом нашего анализа стали заголовки информационных и аналитических медиатекстов, в которых используются устойчивые выражения или в состав которых входят фразеологизмы в широком понимании данного термина: паремии, крылатые выражения и афоризмы, составные термины и т. п.

В теории медиатекста одним из основных коммуникативных блоков, или составляющих, считается заголовок. Он, как правило, характеризуется полифункциональностью. Однако среди множества различных функций заголовка в последнее время выделяют только пять: графически-выделительную, информационную, функцию компрессии, эмоционально-оценочную и полифоническую (Duskaeva 196-198). На наш взгляд, термин эмоционально-оценочная функиия включает в себя прагматическую функиию, поскольку оба этих названия используются для интерпретации функции воздействия. Она „определяется нами как способность заголовка производить определенный эффект на реципиента (удивить, озадачить)” (Peškova 137) и „настроить его на определенное восприятие текста" (Taûpova 22). Для осуществления функции воздействия на реципиента адресанту приходится подбирать такой заголовок, который был бы выразительным и привлекательным, а также вызывал у адресата желание прочитать текст полностью. Вероятнее всего, в таком случае более яркими и, значит, более успешными являются заголовки, в которых используются устойчивые единицы речи: фразеологизмы, паремии, крылатые выражения и афоризмы, перифразы и т. п., поскольку это чаще всего экспрессивные выражения, вызывающие у реципиента множество эмоций, ассоциаций, разного рода воспоминаний.

Эмоционально-оценочный потенциал заголовка организует активное коммуникативное общение с читателем [...], как первый элемент любого текста нацелен на убеждение адресата, формирование у него определенных установок. [...] Разные элементы заголовка, использующие выразительные средства, выступают в роли активатора потенциальных действий читателя (Duskaeva 198).

Некоторые лингвисты называют их прецедентными текстами. Они являются воспроизводимыми единицами языка, которые считаются фоновыми, как правило, общими для адресата и адресанта знаниями. Соответственно у такого заголовка прагматическая функция будет доминирующей, а значит, его можно классифицировать как прагматический заголовок (Кožina 31). Безусловно, одновременно он будет выполнять и другие уже второстепенные функции, например, информационную, номинативную, разделительную, аттрактивную и т. д. Данные устойчивые единицы речи Валерий Михайлович Мокиенко и Константин Павлович Сидоренко предложили называть интертекстемами. Вслед за ними этот термин теперь употребляется и другими 
учеными (напр. Kazak, Mahova 98). В данной работе устойчивые выражения, используемые в качестве заголовков к газетным веб-медиатекстам, мы также будем называть интертекстемами.

Итак, наше исследование заголовков-интертекстем было произведено на основе метода сплошной выборки материала. Именно для данной статьи нами было проанализировано 184 заголовка-интертекстемы из „БелГазеты” (далее БГ) и 190 из „Российской газеты” (далее РГ). Собранный фактический материал показал, что в „Российской газете” чаще всего для заголовков используются собственно фразеологизмы (44\%), крылатые выражения и афоризмы (они составили $34 \%$ от общего числа устойчивых выражений). Однако в „БелГазете” наиболее продуктивными в употреблении стали крылатые выражения и афоризмы (их количество занимает 43\%), а собственно фразеологизмы составили 34\% от общего числа проанализированного фактического материала. Кроме того, в качестве заголовков к веб-медиатекстам примерно с одинаковым соотношением используются паремии $(13 \%: 13,5 \%)$ и составные термины $(7,9 \%: 6,5 \%)$. Обратимся к примерам.

В исследуемых веб-медиатекстах белорусской и российской газет в качестве заголовков применяются как нетрансформированные фразеологизмы, так и обновленные устойчивые сочетания слов: Медвежья услуга (РГ $19.01)$ - 'непрошенная, неумелая и неуместная помощь', Ничего святого (РГ 20.02) - (нет) ничего святого 'безнравственный, аморальный человек или поступок', Проходной двор (РГ 19.01) - 'место или организация, куда можно свободно войти и выйти'; Если бы да кабы (БГ 27.03) - 'реплика, подчеркивающая неосуществимость чего-либо, несбыточность мечты, надежды и т. п.', Абое рабое (БГ 10.04) - 'одинаковые, один не лучше другого', Сорок сороков (БГ 19.06) - 'вся совокупность московских храмов, многочисленность церквей в старой Москве, а также большое количество чего-нибудь' и т. д.; Явка ${ }^{2}$ била рекорды (РГ 20.03) - побить рекорд 'превзойти, перещеголять'; Дать жару в танце (РГ 20.02) - задать жару 'жестоко расправиться с кем-нибудь'; Код в мешке (РГ 23.01) - купить кота в мешке 'приобретать, получать что-либо, заранее не имея представления о качестве получаемого'; Файл преткновения (БГ 21.08) - камень преткновения 'тяжелое препятствие на пути к достижению цели'; На те же грабли (БГ 16.10) наступить на те же грабли (дважды) 'совершить повторную ошибку, не

${ }^{1}$ Семантика устойчивых сочетаний приводится по различным современным электронным и печатным лексикографическим и фразеографическим работам, ссылки на которые в данной работе отсутствуют в связи с ограничениями в объеме публикуемых материалов.

${ }^{2}$ В данном и последующих абзацах статьи полужирным шрифтом и курсивом выделены компоненты заголовков, подвергшиеся различным модификациям. Типы трансформаций не указываются, поскольку это не являлось целью нашего исследования. 
сделав выводы из первого промаха'; ЦИК на дроие (БГ 27.02) - иырк на дроuе 'абсурдный поступок, случай, разговор' и т. п. Думается, здесь уместно подчеркнуть, что только 7\% собранных заголовков-фразем не подверглись никаким трансформациям в „БелГазете”, а в „Российской газете” за 2018 год такие наименования заняли всего около $10 \%$ от общего количества собранного фактического материала.

Кроме того, довольно продуктивными в заголовках веб-медиатекстов являются трансформированные, а также не измененные журналистами крылатые выражения и афоризмы: Без флага и упрека (БГ 27.02) - рыцарь без cтраха и упрека, от франц. le chevalier sans peur et sans reproche; Ничто не ново под луной (БГ 06.03) - фраза из стихотворения Опытная Соломонова мудрость, или Выбранные мысли из Екклезиаста (1797) Николая Михайловича Карамзина; Не комсомолка, но спортсменка (БГ 13.03) - „Комсомолка, спортсменка и просто красавица" - цитата из советской кинокомедии режиссера Леонида Гайдая Кавказская пленница, или Новые приключения Шурика; Не сыпь мне СОМ на раны (БГ 10.04) - „Не сыпь мне соль на рану”строчка из песни Вячеслава Добрынина; Пусть сначала будет слово (РГ 20.02) - „В начале было слово” - первая строка Евангелия от Иоанна (Новый завет); Только папа может (РГ 19.01) - „Папа может, папа может все, что угодно" - слова из детской песни поэта Михаила Танича и композитора Владимира Шаинского; Чистые труды (РГ 15.02) - Чистые пруды - название песни Игоря Талькова и др. В данной группе устойчивых выражений, используемых в качестве заголовков к медиатекстам обеих газет, встречаются в основном обновленные крылатые слова и афоризмы. Не изменили свою внешнюю форму всего лишь 6,3\% (из РГ) и $11,9 \%$ (из БГ) устойчивых сочетаний.

Практически то же мы можем сказать, проанализировав употребленные журналистами в составе заголовков пословицы и поговорки: Не все \#теtоo масленица (БГ 06.02) - Не все коту масленица; Хоть шерсти клок (БГ 16.01) - С паршивой овцы хоть шерсти клок; Любите мучить, любите и денежки платить (БГ 03.04) - Любишь кататься - люби и саночки возить; Разговор дороже денег (РГ 29.12) - Уговор дороже денег; Не творчеством единым (РГ 14.12) - Не хлебом единым жив человек; Совсем один в поле (РГ 24.06) - Один в поле не воин. Из данной группы устойчивых выражений не подверглись формальным изменениям только $1,5 \%$ (в РГ) и $0,5 \%$ (в БГ) паремий.

В „БелГазете” и „Российской газете” составные термины также довольно часто претерпевают обновления: Шутка массового торможения (БГ 30.01) - оружие массового поражения 'оружие крайне большой поражающей способности, предназначенное для нанесения массовых потерь или разрушений 
на относительно больших пространствах и площадях'; Принциип домино (БГ $17.07)$ - принциип домино 'распространяющиеся по цепочке (цепная реакция) определенные явления под действием какого-либо фактора, который влияет на первый элемент цепи'; Притупилась зона турбулентности (БГ 16.01.) зона турбулентности 'участок пространства с неоднородными вихревыми потоками, в которых воздушные массы изменяют скорость и направление'; Бросок через Дидро (РГ 23.01) - бросок через бедро 'прием в дзюдо, самбо'; Первая полоса препятствий (РГ 20.03) - полоса препятствий 'полоса местности, оборудованная различными препятствиями и инженерными сооружениями'; Загсы попадут в облако (РГ 28.06) - попасть (войти) в облако ‘зайти в хранилище файлов в Интернете, в облачный сервер' и др. В качестве заголовков в неизмененной форме применяется, примерно, $1 \%$ (из РГ) и 2\% (из БГ) специальных наименований.

Таким образом, в обоих случаях авторы медиатекстов стараются заинтриговать своих читателей трансформированными формами устойчивых выражений, проявляя при этом приблизительно одинаковый процент креативности: 81\% (РГ) и 78,3\% (БГ). Интересно, на наш взгляд, наблюдать, как российские и белорусские журналисты обновляют языковой фразеологический фонд, приспосабливая его к своим целям и задачам: молочные реки и кисельные берега: Молочные реки и надежные берега (РГ 29.06) - Молочные войны, нацистские берега (БГ 10.04); яблоко раздора: Купальник раздора (РГ 14.06) - Молочный раздор и спадар Помидор (БГ 20.03); Ла-ла лэнд: Лу-лу-лэнд (РГ 31.08) - Пу-Пу-Лэнд навсегда (БГ 20.03); „Поэтом можешь ты не быть, а гражданином быть обязан": Тунеядием можешь ты не быть (БГ 30.01) - А программистом быть обязан (РГ 20.03), Бандитом можешь тыл не быть, но отсидеть лет пять обязан (БГ 17.04); Хлеб - всему голова: Печень всему голова? (РГ 29.06) - Центр всему голова (БГ 20.02), Гендер не всему голова (БГ 16.10); Язык - мой враг: Язык мой - друг твой (РГ 29.06), Язык мой - Трамп мой (БГ 17.07); Преступление и наказание: Преступление без наказания (РГ 21.12) - Исправление и наказание (БГ 19.06) и др.

О большой популярности при использовании в качестве заголовков известных устойчивых фраз свидетельствует их повторное употребление. В „Российской газете”, как правило, повторяются афоризмы, являющиеся названиями известных фильмов: Берегись автомобиля - Береги в автомобиле (РГ 22.08), Берегись автомобиля (РГ 27.04); Место встречи изменить нельзя - Место ареста изменить нельзя (РГ 06.07), Место встречи нужно изменить (РГ 20.04); Никто не хотел умирать - Никто не хотел помогать (РГ 22.06), Никто не хотел рисковать (РГ 28.06). В „БелГазете” повторному использованию подвергаются различные по своей природе устойчивые выражения, например, названия известной книги или художественного фильма: 
Унесенные ветром - Унесенные ступором (БГ 19.06), Унесенные индексом (БГ 25.09), Унесенные мифами (БГ 13.03); фразеологизмы: нашла коса на камень: Нашла коса на „Яндекс” (БГ 27.02), Нашла коса на „Яндекс 2” (БГ 27.03), Коса на камень (БГ 26.06; 04.09); крылатые выражения: Казнить нельзя помиловать: Нельзя помиловать (БГ 04.12), Держать нельзя уезжать. Пахать нельзя отдыхать (БГ 26.12), Мстить нельзя помиловать (БГ 16.10), Лечить нельзя наказывать (БГ 17.04), Смягчить нельзя ужесточить (БГ 25.09); Это еще чветочки, а ягодки будут впереди: Ягодки-иветочки, КГБ на точке (БГ 27.02), Цветочки не стали ягодками (БГ 13.03), Ягодки-иветочки с алкоголизмом (БГ 24.04), Батька в ягодках опять (БГ 04.09) и др. Как показывают примеры, наиболее часто к обыгрыванию одних и тех же устойчивых фраз прибегают белорусские журналисты, например, Юрась Дубина или Виктор Федорович. Они пишут преимущественно для рубрики Общество. Иногда такой способ наименования статей выбирается для разделов Хроники недели или События. Оиенки. В них автор медиатекстов не указывается. Материалы с подобными заголовками пишутся от лица редакции газеты.

В отличие от „Российской газеты” в „БелГазете” встречаются заголовки-интертекстемы, в которых смешиваются графические и в том числе лексические системы различных языков (русского и английского, русского и украинского, русского и белорусского), а также используются общеизвестные символы, например, октоторп, или решетка: Не все \#теtоo масленица (БГ 06.02), Сила есть, ума not found (БГ 02.05), Stand ир на высшем уровне (БГ 06.11); Запрягайте, хлопці, рейтинг (БГ 18.09); Бацька, который бросил вызов системе (БГ 06.03), Шишкан вам в хату (БГ 04.09), Бульбу нефтью не испортишь (БГ 27.11), Батька в ягодках опять (БГ 04.09), Сила есть, ума не надта (БГ 21.08), И колется, и батька не велит (БГ 13.03). Таким образом, вероятнее всего, в белорусских СМИ отражается языковая особенность разговорной речи белорусов - трасянка - и, возможно, адресатная и заголовочная политика всего издания. Как нам кажется, для „БелГазеты” данный способ можно назвать специфическим средством воздействия на белорусского читателя. Кроме того, бесспорно, усиливают прагматическую функцию заголовков различные языковые игры, основанные на стилистических приемах, например, парономазии: Неодимом единым (БГ 30.01) - от неодимовый магнит, неодим; Regnum до Харасти доведет (БГ 19.06), где Харасти - фамилия спецдокладчика ООН по Беларуси Миклоша Харасти; а также использование малоизвестных и окказиональных аббревиатур: Не сыпь мне СОМ на раны (БГ 10.04), где СОМ - это сухое обезжиренное молоко; У вас УСР отклеился (БГ 15.05), где УСР - это устойчивый сбалансированный рост; Национальная МВДея (БГ 29.05), где МВДея образовалась от смешения понятия национальная идея и сложносокращенного слова 
МВД как реакция на события недели; АПК-бароны опять в седле (БГ 24.07), где АПК - это аграрно-промышленный комплекс и др. Такие компоненты заголовков часто являются фонетически созвучными со словами, входящими в состав устойчивых выражений: не сыпь мне соль на рану, у вас ус отклеился, начиональная идея, что позволяет читателю, фактически не задумываясь, ассоциировать заголовок с интертекстемой.

Вместе с тем анализ заголовков „БелГазеты” показывает на то, что в основной коммуникативный блок медиатекстов включаются фразы из нелитературного фонда языка - просторечные, жаргонные и арготические компоненты устойчивых выражений: Шиш уже без масла (БГ 27.03) - шиш с маслом (прост. иронич.); На посошок (БГ 29.05) - на посошок (прост. шутл.); Гарант и таможня дают добро (БГ 26.12) - давать добро (прост.); За „Боинг” ответят (БГ 29.05) - отвечать за базар (жарг); Зайчик в тумане (БГ 13.11) - ежик в тумане (жарг. мол. шутл.); Елки да палки - для „сочиалки” (БГ 24.07) - елки-палки (арг.); Раскатали губу (БГ 14.08) - раскатать губу (арг.) и др. В „Российской газете” данный прием тоже приобретает популярность, поскольку происходит общая тенденция жаргонизации русского языка: Пентагон точит ножи (РГ 19.01) - точить ножи (прост.), Дать жару в танще (РГ 20.02) - задать жару (прост.) и т. д.

Лингвокультурологическое значение, по нашему мнению, будут иметь заголовки, в основу которых легли национальные устойчивые выражения: Золата - самае маё (БГ 06.02) - из популярной рекламы Беларуси: Беларусь-самае маё; Смешныя людзі (БГ 23.01) - название спектакля-комедии Юрия Пахомова, созданного по трем произведениям Антона Павловича Чехова, премьера которого состоялась в Витебске; Страна победившего референдума (БГ 10.04) - перифраза к названию страны Беларусь; Абое рабое (БГ 17.04) - собственно белорусский фразеологизм; Хавайся в „Хельсинки 2" (БГ 29.05) - образован от собственно белорусского устойчивого выражения хавайся у бульбу; Битва под Оршей-2 (БГ 21.08) - название знаменитого исторического сражения, произошедшего 8 сентября 1514 г. во время русско-литовской войны, и т. п. Такие заголовки в „БелГазете” являются непродуктивными наименованиями, однако их использование непосредственным образом указывает на адресацию издания - белорусских читателей, для которых данные устойчивые выражения хорошо знакомы.

Постоянное развитие языка ведет к изменениям в его системе, происходящим преимущественно на уровне его функционирования в различных сферах жизнедеятельности человека. Поэтому неслучайно среди ученых очень актуальной и востребованной задачей является изучение языка в его прагматической функции, а именно проведение исследований, направленных на анализ языковых единиц как средства воздействия на поведение и сознание 
людей в процессе общения. Это значит, что основная цель прагматики - наблюдать и анализировать язык в действии, ориентируясь на изучение речевой коммуникации (Maslova 73, 30). Например, Дмитрий Некрасов в своей работе уже попытался представить медиатексты как речевые произведения, а заголовки к ним - как основной текстовый компонент, соответствующий информативному, репродуктивному, волюнтивному, реактивному и генеритивному коммуникативным регистрам (Nekrasov 121).

Поскольку ядром прагматики считается теория речевых актов, то нашей задачей мы видим обращение внимания именно на высказывания-действия, или перформативы. Как известно, речевой акт обычно имеет три фазы: локутивную, иллокутивную и перлокутивную. Локутивный уровень считается актом произнесения и построения высказывания по грамматическим правилам языка. Иллокутивный уровень - это фаза, придающая речи целенаправленный характер, а перлокутивный акт является своеобразной реакцией на речевое поведение (Maslova 51). Таким образом, мы попробуем продемонстрировать заголовки веб-медиатекстов, выполняющих прагматическую функцию, в роли указателей на основные типы речевых актов - прямые и косвенные. Под прямыми речевыми актами мы понимаем высказывания, используемые в прямом значении, а под косвенными речевыми актами будем подразумевать выражения, употребляемые с переносной семантикой. Кроме того, мы попытаемся распределить заголовки веб-медиатекстов по основным типам речевых актов. Такая классификация стала возможной на том основании, что „интенциональные установки заголовка как сильной позиции текста коммуникационно значимы и обусловливают вектор осмысления произведения в целом" (Duskaeva 196).

Следует подчеркнуть, что в лингвистической литературе нет общепринятого и однозначно определенного количества типов речевых актов. Существуют различные их классификации, которые описываются многими учеными, занимающимися данным вопросом: Валентином Валентиновичем Богдановым (Bogdanov 145-155), Нэллой Аркадьевной Трофимовой (Trofimova 7-13, 53-54) и др. Мы же в своей работе будем использовать классификацию, предложенную Натальей Ивановной Формановской. За основу своей систематизации она взяла типы речевых актов, выделенными Джоржем Серлем (последователем теории речевых актов Джоржа Остина), и дополнила ее еще двумя типами иллокутивных актов. Таким образом, получилась, как нам кажется, типология, вмещающая в себя основные группы целенаправленных высказываний. Итак, мы, вслед за Формановской, будем различать: 1) репрезентативы - сообщения; 2) директивы - побуждения; 3) комиссивы - обязательства; 4) экспрессивы - выражения эмоций; 5) декларативы - объявления; 6) рогативы - вопросы; 7) контактивы - этикетные выражения (Formanovskaâ 
117). Безусловно, представленный список типов речевых актов не является окончательным и законченным, поскольку любое высказывание можно интерпретировать как речевой акт, выполняющий различные коммуникативные задачи, или любая фраза может быть семантически переосмыслена в зависимости от конкретной ситуации общения, контекста и т. д., а значит, может относиться к различным типам речевых актов (Erofeeva 2013). Данное положение соответствует перформативной гипотезе, выдвинутой учеными еще в середине прошлого века. Она основана на концепции „языков-игр” Людвига Витгенштейна, согласно которой значения слов зависят от их употребления в различных контекстах (Vitgenštejn). Данная теория предполагает, что „все глаголы являются потенциально перформативными и все предложения представляют собой потенциальные речевые акты” (Rudnev 514).

По мнению исследователей медиадискурса, заголовок не только именует текст, информирует и готовит читателя к прочтению целого произведения, но и по известным языку формальным показателям заранее предопределяет его речевую установку или цель. Интенция адресанта будет легко определяемой, если в высказывании употребляется глагол, выражающий действие, или, как в нашем случае, устойчивое сочетание является глагольным по грамматическому признаку - в соответствии с определенной частью речи. Например, Сообразили на троих (БГ 27.02) - 'выпили'; Когда сжигают мосты (БГ 20.03) - 'когда решительно порывают с прошлым'; Сделают вливание (РГ 20.03) - 'накажут, отругают'; Кавальеро выходит из тени (РГ 20.02) 'перестает скрываться, привлекать к себе внимание' и т. д. Кроме того, к веб-медиатекстам сравнительно часто журналисты подбирают заголовки, соотносимые с неполными предложениями, где глагол может только подразумеваться, однако он легко восстанавливается по контексту фразы: Правозащитники на острие (БГ 16.01) - на острие атаки, 'были в самой гуще событий’; Шутки в сторону (БГ 23.03) - отбросить шутки, перестать шутить, 'предложение перейти к серьезному разговору'; Деньги на ветер? (РГ 05.07) - деньги пускать на ветер, 'разбрасываться деньгами, сорить деньгами'; Петарда из-под полы (РГ 25.12) - петарды продают 'незаконным способом'. В заглавии-интертекстеме ключевым словом может быть девербатив, также без каких-либо трудностей заменяемый глаголом: За обман в ответе город (РГ 10.08) - за обман отвечает город; Разговор „,о душам” на 8 лет (БГ 24.04) - разговаривать 'откровенно, ничего не скрывая'.

Обратимся к анализу заголовков, в состав которых входят глаголы или легко подразумеваются в соответствии с тождественными им типами иллокутивных речевых актов. Итак, репрезентативами (ассертивами) принято называть речевые акты, выполняющие информативную функцию. В данном случае, как отмечают исследователи, могут употребляться глаголы изъя- 
вительного и сослагательного наклонения, а также имплицитные перформативы. Например: Притупилась зона турбулентности (БГ 16.01), Когда финансы не догоняют вал (БГ 20.03), „Динамо” дали по рукам (РГ 19.01), Обещанного ждала три года (РГ 15.02), Явка била рекорды (РГ 20.03) и др. Как видно из вышеприведенных заголовков, их глагольные компоненты чаще всего имеют форму прошедшего времени, называя действие как свершившийся факт.

Рогативами, как правило, называются такие речевые акты, в содержании которых заключен вопрос: За чей счет банкет? (БГ 30.01), Без права на ульббку? (БГ 20.02), Зачем козе баян (БГ 27.03), Что ищет он? (РГ 20.02), Что у бизнеса на уме (РГ 10.01), Бит или не бит? (РГ 15.02). В данном случае заголовки соответствуют прямому вопросу или его подразумевают, поскольку в состав такой фразы входят вопросительные местоимения и наречия. Они оформляются по образцу и вопросительных предложений, и обычных названий текстов.

На наш взгляд, так же довольно продуктивным типом являются заголовки, указывающие на директивный тип речевого акта, поскольку они, как правило, имеют побудительный характер, выражающийся в форме повелительного наклонения глагола 2-го лица множественного и единственного числа: Гоните наши денежки! (БГ 13.02), Крути педали (БГ 27.02), Кукла Мама, не плачь (БГ 24.04), Держи рот на замке (РГ 31.08), Беги, Поло, беги (РГ 05.07), Давайте дружить чипами (РГ 20.04) и под.

Речевые акты, называющиеся комиссивами, обязывают других сделать что-либо, дать обещание или клятву. По этой причине в состав заголовков, указывающих на подобный тип, как правило, входят синтетические формы глаголов будущего времени: Медведь не прошмыгнет (БГ 05.06), Не оставят в беде (РГ 20.02), Сносу не будет (РГ 22.08.), А программистом быть обязан (РГ 20.03), Как только - так сразу (БГ 14.08) и др.

Контактивами, по мнению Формановской, следует считать этикетные выражения, в том числе и обращения (Formanovskaâ 117). На этом основании к данной группе мы можем отнести такие заголовки, как Привет с большого Белуна (БГ 30.10), И снова здравствуйте (БГ 17.07), Здравствуйте, мы ваша крыма (БГ 21.08), Наме вам с пакетом (БГ 30.01), На долгую жизнь (РГ 06.07), С новым снегом (РГ 29.12) и некоторые другие.

Экспрессивами принято считать выражения, передающие эмоции и психическое состояние говорящего: Клин клином, смех смехом (БГ 13.03), Опять двадиать пять (БГ 17.07), За „Боинг” ответят (БГ 29.05), Дать жару в танце (РГ 20.02), Пальиы веером (РГ 19.01), Штамп ставить неку$\partial a$ (РГ 23.01). Чаще всего встречаются выражения, передающие негативные эмоции, несущие значение неодобрения и даже угрозы. 
Цель декларативов - сделать объявление, декларацию, дать назначение. Несмотря на то, что в „Российской газете” очень часто публикуются тексты государственных документов и законов, заголовки такого типа с интертекстемами в ней не являются продуктивными. Похожая ситуация с использованием декларативов наблюдается и в „БелГазете”. Таким образом, заголовки веб-медиатекстов „БелГазеты” и „Российской газеты”, выполняющие прагматическую функцию, - это своеобразные указатели на речевые акты, предопределяющие стиль и способ коммуникации адресанта и адресата, а также выражающие главную цель высказывания.

На наш взгляд, не относятся к иллокутивному речевому акту заголовки номинативного характера, именующие определенное событие или факт и одновременно дающие им оценку: Медвежья услуга (РГ 19.01), Дети пол$к а$ (РГ 10.01), Бедная Анна (БГ 23.01), Эффект бабочки (БГ 27.03) и др., или заголовки, имеющие адъективный характер, выдвигающие на первый план определенный признак какого-либо действия: Легкий на подъем (РГ 23.01) 'делающий что-то с легкостью и охотно'; По букве закона (РГ 20.03) - 'согласно закону, правильно'; Живее всех живых (БГ 13.02) - 'самый актуальный'; Без флага и упрека (27.02) - 'смелый, безукоризненного поведения'; Между камнями и клубнями (БГ 20.03) - 'в тяжелом положении' и под. Такие заголовки мы предлагаем относить к косвенным речевым актам, носящим перлокутивный характер, поскольку они отображают реакцию адресанта на определенное действие, событие или факт, не называя его прямо, а, скорее всего, именуя метафорически.

Итак, из всего вышесказанного мы можем сделать следующие выводы:

1. Заголовки веб-медиатекстов, в состав которых входят интертекстемы, имеют, как правило, доминирующую прагматическую функцию. На наш взгляд, она усиливается, когда журналисты используют интертекстемы из нелитературного фонда языка, а также когда в названиях текстов сочетаются различные графические системы - кириллическая и латинская; когда в состав заголовков включаются окказионализмы, в том числе имеющие вид сложносокращенного существительного, или в названии заголовка используется какой-либо прием языковой игры.

2. Являясь полноправным компонентом медиатекста, заголовок уже изначально формирует его целостное восприятие, намекает на предстоящий тип речевой коммуникации. Предложенная попытка сделать классификацию заголовков, выступающих в роли указателей на основные типы речевых актов, была осуществлена на основе уже известных прагмалингвистике формальных (грамматических) показателей без учета их полного внутреннего содержания или семантического анализа веб-медиатекстов, поэтому, на наш взгляд, еще требует дальнейшего исследования. Однако данный предвари- 
тельный анализ заголовков-интертекстем показал, что в исследуемых газетах чаще всего используются заголовки иллокутивного косвенного характера, подразумевающие репрезентативный, рогативный, директивный и комиссивный типы речевых актов. Контактивный и экспрессивный типы являются менее продуктивными, а декларативный тип заголовков в „БелГазете” и „Российской газете”, как правило, используется очень редко. Перлокутивная фаза между коммуникантами отражается в заголовках-интертекстемах номинативного и адъективного характера, которые мы также относим к косвенным речевым актам.

\section{Библиография}

Bogdanov, Valentin V. Predloženie i tekst v soderžatel'nom aspekte. Sankt-Peterburg, Filologičeskij fakul'tet Sankt-Peterburgskogo gosudarstvennogo universiteta, 2007.

Duskaeva, Liliâ R., red. Medialingvistika v terminah i ponâtiâh: slovar'-spravočnik. Moskva, Flinta, 2018.

Erofeeva, Elena V. Pragmatičeskie aspekty rečevyh aktov različnoj kommunikativnoj napravlennosti v sovremennom francuzskom âzyke. Moskva, AGBOU VPO „Urgpu”, 2013.

Formanovskaâ, Nataliâ I. Rečevoe obŝenie: kommunikativno-pragmatičeskij podhod: učebnoe posobie. Moskva, Russkij âzyk, 2002.

Kazak, Mariâ Û., Anna A. Mahova. „Raznotipnye intertekstemy v žurnalistskom tekste: opyt funkcional'nogo opisaniâ". Medialingvistika, 2 (8), 2015, s. 93-103.

Kožina, Nataliâ A. Zaglavie hudožestvennogo proizvedeniâ: struktura, funkciâ, tipologiâ (na materiale russkoj prozy` $X I X-X X v v$.). Dissertaciâ na soiskanie učenoj stepeni kandidata filologičeskih nauk. Moskva, 1986.

Kuz'mina, Natal'â A., red. Sovremennyj mediatekst: učebnoe posobie. Moskva, Flinta, 2014.

Maslova, Alina Û. Vvedenie v pragmalingvistiku: učebnoe posobie. Moskva, Flinta, 2010.

Menŝikova, Ûliâ N. Rečevaâ kommunikaciâ: pragmatičeskij aspekt. Avtoreferat dissertacii na soiskanie učenoj stepeni kandidata filologičeskih nauk. Omsk, Omskij gosudarstvennyj pedagogičeskij universitet, 2008.

Nekrasov, Dmitrij V. „Funkcional'no-pragmatičeskie harakteristiki zagolovkov novostnyh tekstov $\mathrm{v}$ internete (na primere sovremennyh informagentstv)". Filologičeskie nauki. Voprosy teorii i praktiki, 1 (31)/1, 2014, s. 117-123.

Parzulova, Marianna. Medialingvistika: učebnoe posobie. Trnava, Univerzita sv. Cyrila a Metoda, 2016.

Peškova, Ûliâ V. „Funkciâ zagolovkov nemeckoâzyčnyh novostnyh tekstov”. Vestnik Leningradskogo gosudarstvennogo universiteta im. A.S. Puškina, 2012, s. 134-140.

Rudnev, Vadim P. Ėnciklopedičeskij slovar' kul'tury XX veka. Moskva, „Agraf”, 2001.

Taûpova, Ol'ga I. „Pragmatičeskij potencial zagolovkov v sovremennyh publicističeskih tekstah”. Vestnik Voronežskogo gosudarstvennogo universiteta. Seriâ: Lingvistika i mežkul'turnaâ kommunikaciâ, 4, 2015, s. 21-26.

Trofimova, Nèlla A. Èkspressivnye rečevye akty v dialogičeskom diskurse. Semantičeskij, pragmatičeskij, grammatičeskij analiz. Sankt-Peterburg, Izdatel'stvo VVM, 2008.

Vitgenštejn, Lûdvig. „O dostovernosti”. Voprosy filosofii, 2, 1991, s. 67-120. 